Artículo

\title{
Fumigación con ácido acético y antimicrobianos para disminuir mortandad de Chrysoperla carnea por infección indeterminada
}

\author{
José Alfredo Samaniego-Gaxiola ${ }^{1 \S}$ \\ Aurelio Pedroza-Sandoval ${ }^{2}$ \\ Alexandra Bravo ${ }^{3}$ \\ Jorge Félix Sánchez ${ }^{3}$ \\ Guadalupe Peña-Chora ${ }^{4}$ \\ Dolores Mendoza-Flores ${ }^{2}$ \\ Yasmín Chew Madinaveitia ${ }^{1}$ \\ Arturo Gaytán Mascorro ${ }^{5}$
}

${ }^{1}$ Campo Experimental La Laguna-INIFAP. Blvd. José Santos Valdez 1200 Pte, Col. Centro Matamoros, Coahuila, México. CP. 27440. (chew.yazmin@inifap.gob.mx). ${ }^{2}$ Unidad Regional Universitaria de Zonas Áridas-UACH. Carretera Gómez Palacio-Chihuahua km 40, Bermejillo, Durango, México. CP. 56230. (apedroza@chapingo.uruza.edu.mx; mefllola@chapingo.uruza.edu.mx). ${ }^{3}$ Instituto de BiotecnologíaUNAM. Av. Universidad 2001, Chamilpa 62210, Cuernavaca, Morelos, México. (bravo@ibt.unam.mx). ${ }^{4}$ Centro de Investigaciones Biológicas-UAEM. Avenida Universidad 1001, Colonia Chamilpa, Cuernavaca, Morelos, México. CP. 62209. ${ }^{5}$ Depto. de Fitomejoramiento-Unidad Laguna-UAAAN. Periférico Raúl López Sánchez y Carretera a Santa Fé. (gaytan6310@yahoo.com.mx).

${ }^{\S}$ Autor para correspondencia: samaniego.jose@inifap.gob.mx.

\section{Resumen}

Chrysoperla carnea reproducida comercialmente por un laboratorio (CREROB) adquirió una enfermedad infecciosa que mata larvas, pupas y adultos. Para contrarrestar la infección, se evaluó fumigación con ácido acético (AA) en tres dosis y cuatro tiempos a huevos y cuatro dosis y seis tiempos a las pupas; al adulto se le proporcionaron seis sustancias antimicrobianas distintas. De los huevos fumigados de la crisopa se obtuvieron $50 \%$ de adultos respecto a los huevos no fumigados ( $p<0.001)$. En contraste, los adultos provenientes de huevos fumigados sobrevivieron el doble que aquellos no fumigados $(p<0.01)$. Algunos adultos provenientes de huevos fumigados sobrevivieron, pero la fumigación no impidió que se infectaran y posteriormente murieran las crisopas adultas. Después de 51 días tras mantener a los adultos de crisopas con sustancias antimicrobianas (en el agua que bebían) únicamente cefotaxima a dosis de $1200 \mu \mathrm{g} \mathrm{ml}^{-1}$ de ingrediente activo permitió mantener sin síntomas de la infección y 100\% de sobrevivencia. Crisopas tratadas con sustancias antimicrobianas sobrevivieron entre 50 y $81 \%$ mientras que adultos provenientes de huevos fumigados tuvieron una supervivencia menor de 31 y $34 \%$ debiéndose la diferencia a una mayor asepsia de las primeras. De los insectos adultos infectados se aislaron dos cepas de Bacillus thuringiensis y se caracterizaron sus toxinas Cry; aunque no se atribuye la infección de las crisopas a $B$. thuringiensis se discute su presencia.

Palabras clave: Chrysoperla, antimicrobianos, enfermedades, fumigación.

Recibido: mayo de 2019

Aceptado: agosto de 2019 


\section{Introducción}

Las especies de Chrysoperla son ampliamente utilizadas como insectos depredadores de insectos plaga en programas de control biológico, se hacen reproducir en múltiples laboratorios comerciales en diversos países y son parte del manejo integrado de plagas (McEwen et al., 2007). Durante el proceso de reproducción las crisopas pueden adquirir enfermedades que diezmen su población, asociadas a bacterias, hongos, protozoos y virus, aunque en ocasiones, no siempre ha sido posible determinar al agente etiológico (Kleespies et al., 2008; Taber, 2011). Si bien, para Chrysoperla spp., se han encontrado bacterias patógenas como Enterobacter spp. y Bacillus spp., también se han aislado microorganismos endosimbiontes como levaduras, bacterias y hongos filamentosos (Meca et al., 2009; Hemalatha, 2015; Fletcher, 2016).

Asimismo, las larvas de Chrysoperla spp., pueden ser afectadas negativamente por B. thuringiensis o sus toxinas (Hilbeck et al., 1998; Dutton et al., 2003). En el laboratorio de producción de insectos benéficos (CREROB) en Torreón, Coahuila, México, se reproduce Chrysoperla carnea Stephens, en 2012-2013 se presentó una infección mortal en todos los estados insecto, que disminuyó en más de $90 \%$ su producción comercial. Al disectar adultos de C. carnea provenientes del CREROB, dentro del tracto digestivo, se observaron levaduras, bacterias y algunas bacterias con cristales, éstas últimas, como las descritas (Carreras-Solís, 2009).

Por lo anterior, nos preguntamos; i) si las bacterias con cristales dentro de los adultos de C. carnea podrían pertenecer a Bacillus thuringiensis Berliner; y ii) si una alternativa para contener la infección de $C$. carnea podría ser el fumigar sus huevos, pupas o proporcionar antimicrobianos a los adultos. Bacterias, nematodos e insectos son susceptibles al ácido acético, que se han utilizado como fumigante para evitar el deterioro o daño de alimentos y cultivos agrícolas por organismos perjudiciales (Momma et al., 2006; Sholberg, 2009; Katase et al., 2009).

Ante la contingencia presentada en el CREROB, se propuso evaluar tratamientos de fumigación con ácido acético huevos y pupas de C. carnea y de antimicrobianos en los adultos, para contener y prevenir la infección. Asimismo, buscar B. thuringiensis dentro de adultos de C. carnea infectados.

\section{Materiales y métodos}

\section{Manejo de los insectos}

Durante el año 2013, huevos, pupas y adultos de C. carnea fueron proporcionados por el CREROB. Después de recibirlos, huevos y pupas fueron fumigados como se indicará, mientras que a los adultos se les proporcionaron antimicrobianos en el agua que bebieron. Después de la fumigación los huevos fueron incubados a $28^{\circ} \mathrm{C}$ y al eclosionar las larvas fueron alimentadas con huevos de Sitotroga cerealella Olivier, proporcionado por el CREROB. Las pupas fueron incubadas a $28^{\circ} \mathrm{C}$ hasta obtener el adulto a temperatura de laboratorio $\left(20-25^{\circ} \mathrm{C}\right)$.

Los adultos fueron alimentados con una mezcla de azúcar sin refinar, leche en polvo $\left(\mathrm{Nido}^{\circledR}\right)$ y levadura seca de cerveza (Industrial Rosanco ${ }^{\circledR}$ ) en proporción 2:1:1 p/p/p, preparada con agua destilada y calentándola hasta tener la consistencia de una jalea. La jalea fue almacenada durante 15 días a $0{ }^{\circ} \mathrm{C}$. Los adultos fueron alimentados con jalea, sobre abate-lenguas esterilizados 
(renovados cada tercer día) o sobre las paredes de las celdas de confinamiento. A los adultos, se les proporcionó en el agua destilada estéril los antimicrobianos en la cabeza de hisopos estériles, remplazándolos cada tercer día, el testigo solo el agua.

\section{Aislamiento e identificación de Bacillus thuringiensis}

Los adultos de $C$. carnea fueron esterilizados superficialmente con hipoclorito de sodio al $1 \%$ y macerados en condiciones de esterilidad para posteriormente recuperar el macerado en agua estéril. Para observar la formación de los cuerpos paraesporales en microscopio óptico, se crecieron las bacterias en medio nutritivo hasta inducir la esporulación. Después de tres días de crecimiento se recuperaron las esporas y los cristales y se analizaron en un gel SDS-PAGE. Este macerado fue sembrado en placas Petri conteniendo medio Luria-Bertani sólido.

Las placas fueron incubadas a $30^{\circ} \mathrm{C}$ durante $24 \mathrm{~h}$ y fueron identificadas diferentes bacterias, entre estas fueron seleccionadas y purificadas dos aislados denominados $\mathrm{Cc} 1$ y $\mathrm{Cc} 2$ que presentaron la morfología típica de bacterias pertenecientes a B. thuringiensis. Para comprobar que estas corresponden a dicha especie se analizó la amplificación por PCR del gene 16S ribosomal utilizando oligonucleótidos específicos diseñados por (Aguino de Muro y Priest, 1993).

Para identificar ambos aislados, se hicieron crecer durante 12 horas en una placa de medio nutritivo (Difco). Un pequeño volumen de células fue transferido a $0.1 \mathrm{ml} \mathrm{de} \mathrm{H}_{2} \mathrm{O}$ y congelado a $-70{ }^{\circ} \mathrm{C}$ durante 20 min para después ser incubadas en agua hirviendo durante 10 min para lisar las células. El lisado celular resultante se centrifugó brevemente $(10 \mathrm{~s}$ a $10000 \mathrm{rpm}$ en una centrífuga Eppendorf modelo 5415C) y $15 \mu \mathrm{l}$ de sobrenadante fue utilizado como muestra de ADN en la PCR.

La amplificación se hizo en un termociclador Perkin-Elmer modelo 480. Las condiciones de las PCR hechas con oligonucleótidos cry1 (gral-cry1) fueron las siguientes: una sola etapa de desnaturalización de 2 min a $95^{\circ} \mathrm{C}$, seguido de un programa de 30 ciclos en donde cada ciclo consta de desnaturalización a $95{ }^{\circ} \mathrm{C}$ durante un min, hibridación a $52{ }^{\circ} \mathrm{C}$ durante 1 min y extensión a $72{ }^{\circ} \mathrm{C}$ durante un min. $\mathrm{Al}$ final de 30 ciclos se realizó un paso adicional de extensión a $72{ }^{\circ} \mathrm{C}$ durante 5 min.

Las condiciones para las PCR realizadas con los otros oligonucleótidos fueron similares, excepto que se modificaron las temperaturas de hibridación a $49{ }^{\circ} \mathrm{C}$ para oligonucleótidos de cry8, a $51{ }^{\circ} \mathrm{C}$ para oligonucleótidos de cry9, cry 11 y cyt 1 y a $50{ }^{\circ} \mathrm{C}$ para el resto de los oligonucleótidos. Una vez realizada la reacción de amplificación, se sometió a electroforesis en un gel de agarosa al 2\% en tampón Tris-borato (45 mM Tris-borato, $1 \mathrm{mM}$ EDTA (pH 8) a 250 $\mathrm{V}$ por $35 \mathrm{~min}$ y se tiñeron con bromuro de etidio. Finalmente, con la intención de identificar a estas proteínas se realizó un análisis de posibles genes cry presentes en estas cepas utilizando una batería de oligonucleótidos (Cerón et al., 1995; Bravo et al., 1998). Estos oligonucleótidos permiten identificar a genes cry 1, cry 3 , cry 5 , cry 7, cry 8, cry 9, cry 11, cry 13, cry 14 y cyt $1 \mathrm{~A}$.

\section{Bioensayos de patogenicidad en otras especies}

Las actividades de las diferentes cepas de B. thuringiensis se analizaron en larvas neonatas de Spodoptera frugiperda y Diatraea magnifactella (Insecta: Lepidoptera). Diluciones de las suspensiones de esporas-cristales se aplicaron sobre la superficie de la dieta a una concentración final de 100 y $1000 \mathrm{ng} \mathrm{cm}^{-2}$ (Bravo et al., 1998). La mortalidad se registró después de siete días. 


\section{Bioensayos de fumigación en huevo}

Frascos de vidrio de $250 \mathrm{ml}$ fueron utilizados para poner en el fondo ácido acético como fumigante, dentro de este frasco fue colocado un frasco de $25 \mathrm{ml}$ en donde fueron colocados los huevos de $C$. carnea. Las dosis y tiempos de fumigación de los huevos fueron de 0 (testigo) 0.04 y $0.4 \mu 1 \mathrm{ml}^{-1}$ ácido-aire durante 8, 16, 24 y 48 h, respectivamente. En total, cuatro repeticiones fueron utilizadas para cada dosis y tiempo, cada repetición fue conformada por 50 huevos. Posterior a la fumigación, los huevos fueron colocados de manera individual en celdas de alrededor de un $\mathrm{cm}^{3}$, en donde al eclosionar las larvas se alimentaron con huevos de S. cerealella.

Las pupas formadas fueron colocadas en celdas de confinamiento individuales de tres $\mathrm{cm}^{3}$, donde previamente se impregnó la jalea sobre las paredes para alimentar a los adultos que emergieron, suministrándoles también agua estéril e incubándose a temperatura de laboratorio $\left(20-25{ }^{\circ} \mathrm{C}\right)$ durante 35 días. El recuento de adultos vivos sin síntomas y muertos con síntomas se realizó semanalmente y diariamente se retiraron los adultos muertos para evitar en lo posible la diseminación de la infección. Este y posteriores experimentos fueron repetidos dos veces. Otro experimento se realizó de manera idéntica, excepto porque a las larvas se les proporcionó huevos de $S$. cerealella esterilizados con calor.

\section{Bioensayos de fumigación en pupas}

Las pupas fueron fumigadas con ácido acético a dosis de 0 (testigo), 0.04 . 0.4 y $4 \mu 1 \mathrm{ml}^{-1}$ ácidoaire a tiempos de fumigación de 10, 20, 30, 60 y $120 \mathrm{~min}$. Enseguida, fueron confinadas en vasos de poliuretano de un litro, y los adultos emergidos fueron mantenidos por dos semanas a temperatura de laboratorio $\left(20-25{ }^{\circ} \mathrm{C}\right)$, tiempo en el que se contabilizó adultos muertos con síntomas de la enfermedad y adultos sin síntomas. Los adultos fueron alimentados con la jalea en los abate-lenguas y el suministro de agua en los hisopos. Las pupas y adultos muertos fueron retirados diariamente. En total, cuatro repeticiones por cada dosis y tiempo de fumigación de las pupas fueron realizadas, cada repetición con 15 pupas.

\section{Bioensayos con antimicrobianos en adultos}

En el CREROB, se nos proporcionaron diez unidades cada una con 700-800 celdas ocupadas por pupas, de donde se esperaba obtener por lo menos 4200 adultos, para evaluar seis antimicrobianos por tres dosis cada uno (un testigo) con cuatro repeticiones. De las unidades, solo se recobraron 530 pupas de donde nacerían los adultos. Con las pupas disponibles, se establecieron 21 tratamientos con (25 pupas) sin repeticiones, seis sustancias antimicrobianas con tres dosis y el testigo sin antimicrobiano. Después se desechar los adultos muertos en los primeros dos días, los tratamientos contaron con distinto número de adultos (Cuadro 1).

Los productos antimicrobianos de tipo comercial que se utilizaron fueronamikacina Amk ${ }^{\circledR}$ ampicilina Binotal ${ }^{\circledR}$; cefotaxima Biosint ${ }^{\circledR}$, eritromicina Ilosone ${ }^{\circledR}$, metronidasol Flagelase $^{\circledR}$, vancomicina Vancocin ${ }^{\circledR}$ además del testigo.

Las pupas y los adultos emergidos se confinaron en vasos de poliuretano de $2 \mathrm{~L}$, diariamente se retiraron adultos muertos cuando los hubo. A las crisopas se les proporcionó el alimento en abatelenguas con la jalea, mientras los antimicrobianos en el agua que retenían los hisopos. Los insectos 
se transfirieron temporalmente a otro vaso, mientras que el vaso de origen se limpió utilizando algodón embebido con una solución de cloro comercial al $0.3 \%$. La primera limpieza se realizó siete días después de haber emergido los adultos, las subsecuentes cada cinco días.

Cuadro 1. Tratamientos y dosis de sustancias antimicrobianas evaluadas contra adultos de Chrysoperla carnea.

\begin{tabular}{lcc}
\hline Sustancia antimicrobiana & Dosis $\left(\mu \mathrm{g} \mathrm{m}^{-1}\right)$ & Núm. adultos iniciales \\
\hline Amikacina & 25 & 15 \\
& 50 & 12 \\
Ampicilina & 100 & 19 \\
& 150 & 15 \\
Cefotaxima & 300 & 8 \\
& 600 & 9 \\
& 300 & 14 \\
Eritromicina & 600 & 5 \\
& 1200 & 13 \\
Metronidasol & 100 & 15 \\
& 200 & 13 \\
Vancomicina & 400 & 16 \\
& 100 & 20 \\
Testigo 1 & 200 & 7 \\
Testigo 2 & 400 & 14 \\
Testigo 3 & 50 & 16 \\
\hline
\end{tabular}

\section{Análisis de datos}

Los datos de adultos obtenidos de los experimentos de las fumigaciones de huevos se analizaron por la prueba de chi cuadrada $\left(\chi^{2}\right)$. El experimento con pupas se analizó con un diseño completamente al azar, un arreglo factorial y con el procedimiento GLM, en donde el tiempo de fumigación y la dosis fueron los factores; cada análisis se realizó por separado para los tiempos de incubación de 7 y 14 d. El experimento de adultos tratados con antimicrobianos no se analizó estadísticamente debido a la falta de repeticiones.

De los insectos adultos que provenían de los huevos fumigados, se establecieron sus coeficientes de determinación lineal $\mathrm{R}^{2}$ y sus pendientes, ello para su supervivencia versus tiempo de incubación. También se obtuvo $\mathrm{R}^{2}$ entre las pendientes obtenidas para cada tratamiento (en cada experimento) incluyendo los testigos versus número inicial de insectos adultos. Todos los análisis se realizaron con el Sistema de Análisis Estadístico (SAS versión 9.1, 2003). 


\section{Resultados}

\section{Sintomatología de la enfermedad}

Los adultos de $C$. carnea infectados ralentizan su movimiento, su tórax se torna oscuro, posteriormente también todo el tracto digestivo; el insecto no ingiere alimento y adelgaza hasta morir (Figura 1 A y B), cuando ello ocurre, la descomposición del insecto genera un olor fétido. Pupas y larvas también se tornan oscuras y mueren (Figura 1C y 1D).
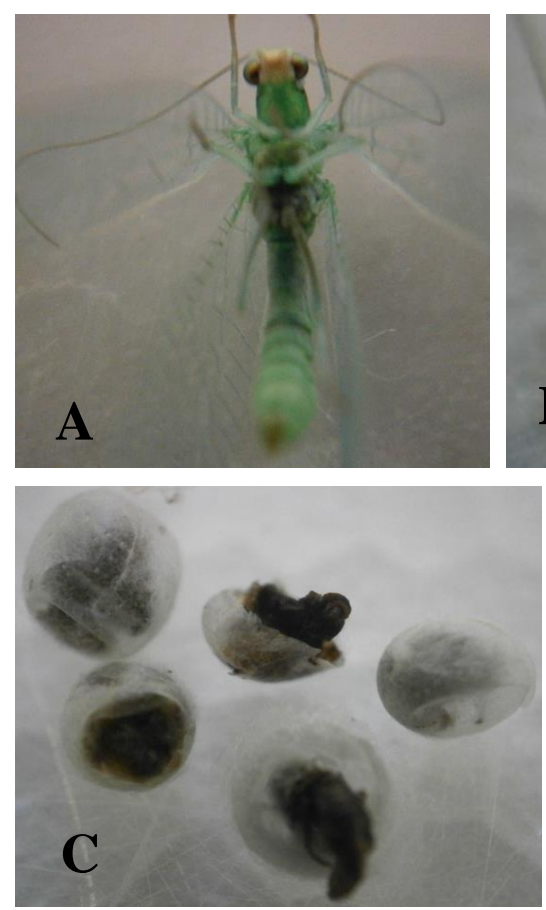

Figura 1. A-D) signos de infección en Chrysoperla carnea. A) adulto con tórax oscurecido y abdomen ceñido; B) adulto con abdomen muy oscurecido; C) pupas con producto muerto y oscurecido; y D) larva muerta y oscurecida.

\section{Aislamiento e identificación de Bacillus thuringiensis}

Las colonias bacterianas aisladas fueron de color blanco, opaco, estrellada y plana. El producto de PCR obtenido mostró el tamaño (dato no mostrado) propio del grupo de Bacillus spp. También se observaron los cuerpos paraesporales, característica única de B. thuringiensis (donde las proteínas Cry o Cyt se acumulan).

La Figura 2, muestra que la cepa Cc1 produce una proteína de $150 \mathrm{kDa}$ y la cepa Cc2 presenta un cristal muy pequeño, por lo que es difícil identificar la banda del cristal en el gel SDS-PAGE, notando solamente que presenta una proteína de $65 \mathrm{kDa}$ que asemeja el peso de otras proteínas $C r y$ reportadas en $B$. thuringiensis. La cepa $\mathrm{Cc} 2$ presento amplificación con los oligonucleótidos del gene cry3. Sin embargo, no se observó una proteína de peso similar a lo observado con la cepa control que expresa Cry3Aa. La cepa Cc1 no amplificó con ninguno de estos oligonucleótidos. Estos datos sugieren que estas cepas podrían contener genes diferentes a los analizados por medio de estos ensayos de PCR o podrían contener un posible gen cry nuevo. 


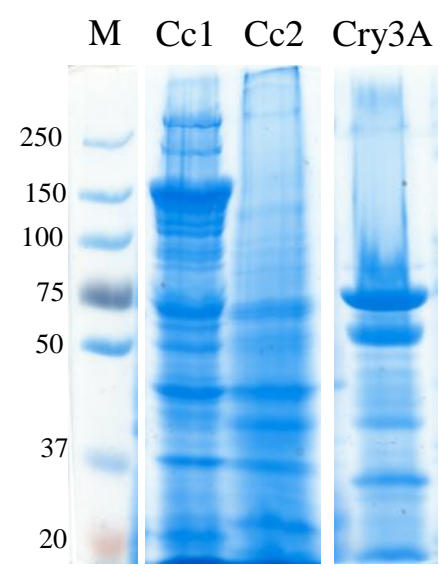

Figura 2. Gel de SDS-PAGE que muestra un peso molecular diferente de las proteínas formadoras de cristales en las cepas $\mathrm{Cc1}$ y $\mathrm{Cc} 2$ con respecto a las proteínas $C r y 3 A$ de $B$. thuringiensis.

\section{Bioensayos de patogenicidad en otras especies}

La toxicidad de las cepas de Bacillus spp. incluyendo a dos cepas de B. thuringiensis probada contra $S$. frugiperda y $D$. magnifactella mostraron que no son toxicas para estas especies de insectos, si bien, la toxicidad de las cepas de B. thuringiensis no se ensayaron contra larvas y adultos de $C$. carnea.

\section{Bioensayos de fumigación en huevo}

En el primero y segundo experimentos, los tratamientos testigo sin fumigar y fumigados se recobraron 19, 17 y 8, 8\% de adultos, respectivamente (Figura 3 izquierda). Las diferencias entre los tratamientos fueron significativas $\left(X^{2}=74.6, \mathrm{gl}=8, p<0.001\right)$ para el primer experimento y $\left(\chi^{2}\right.$ $=109.6, \mathrm{gl}=8, p<0.001)$ para el segundo experimento. Después de cinco semanas, la supervivencia de los adultos que provenían de huevos fumigados fue el doble que el testigo huevos no fumigados (Figura 3 derecha) en el primer experimento $\left(\chi^{2}=36.9, \mathrm{gl}=9, p \leq 0.001\right)$ y $\left(\chi^{2}=26.6, \mathrm{gl}=9, p \leq\right.$ 0.001 ) en el segundo.
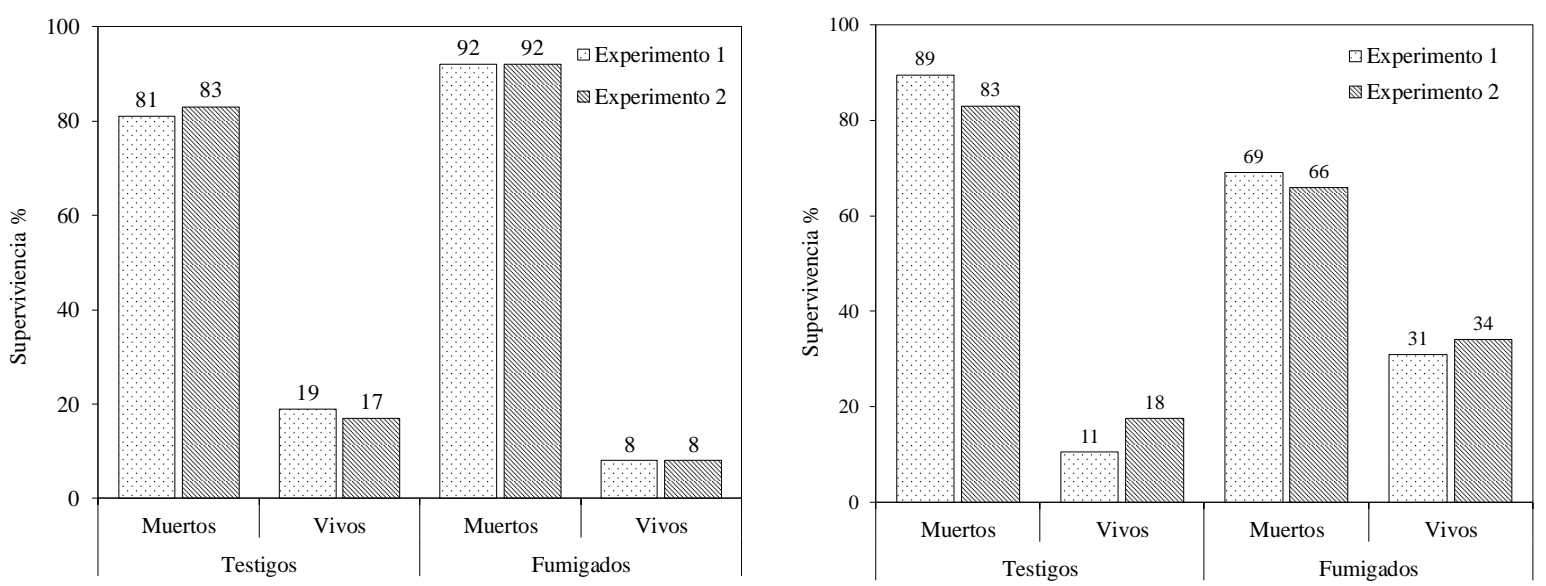

Figura 3. Sobrevivencia de adultos vivos y muertos de $C$. carnea. Izquierda, adultos vivos o muertos que provenían de 1600 huevos fumigados o de 200 huevos no fumigados testigo en dos experimentos. Derecha, adultos vivos o muertos después de cinco semanas de incubación. 
Para cada curva (lineal) de supervivencia versus número inicial de adultos sanos, se obtuvieron sus pendientes, $\mathrm{R}^{2}$ y su bondad de ajuste (Cuadro 2), ahí se observa que en ambos experimentos el tratamiento huevo fumigado con $0.4 \mu \mathrm{ml}^{-1}$ ácido-aire por $16 \mathrm{~h}$ no fue significativa la bondad de ajuste de sus pendientes; el resto de los tratamientos y testigo fueron significativos.

Cuadro 2. Pendientes, coeficientes de determinación $\mathbf{R}^{2}$ y ajuste $\chi^{2}$ de las relaciones supervivencia versus tiempo de incubación de los adultos de $C$. carnea. Los adultos provenientes de huevos se les aplicaron tratamientos de fumigación durante distintos tiempos.

\begin{tabular}{|c|c|c|c|c|c|c|}
\hline \multirow{2}{*}{ Tratamientos $€$} & \multicolumn{3}{|c|}{ Experimento 1} & \multicolumn{3}{|c|}{ Experimento 2} \\
\hline & Pendientes & $\mathrm{R}^{2}$ & $£ \chi^{2}$ & Pendientes & $\mathrm{R}^{2}$ & $\chi^{2}$ \\
\hline $0.04 \mathrm{~T} 8$ & -0.759 & 0.991 & $* * * *$ & -1.033 & 0.977 & **** \\
\hline $0.4 \mathrm{~T} 8$ & -0.416 & 0.957 & **** & -0.208 & 0.957 & **** \\
\hline $0.04 \mathrm{~T} 16$ & -0.314 & 0.953 & *** & -0.188 & 0.856 & $* * *$ \\
\hline $0.4 \mathrm{~T} 16$ & 0 & 0 & ns & -0.037 & 0.771 & ns \\
\hline $0.04 \mathrm{~T} 24$ & -0.294 & 0.912 & **** & -0.131 & 0.757 & $* * *$ \\
\hline $0.4 \mathrm{~T} 24$ & -0.033 & 0.686 & **** & -0.053 & 0.852 & **** \\
\hline $0.04 \mathrm{~T} 48$ & -0.31 & 0.945 & **** & -0.457 & 0.971 & $* * *$ \\
\hline $0.4 \mathrm{~T} 48$ & -0.682 & 0.966 & **** & -0.269 & 0.982 & **** \\
\hline Testigo & -0.988 & 0.966 & **** & -0.833 & 0.982 & $* * *$ \\
\hline
\end{tabular}

$€=$ los tratamientos fueron huevos que se fumigaron con ácido acético a dosis de 0 o testigo, 0.04 y $0.4{\mathrm{de} \mu 1 \mathrm{ml}^{-1}}^{-1}$ ácido-aire, en tiempos de fumigación de $8 \mathrm{~T} 8,16 \mathrm{~T} 16,24 \mathrm{~T} 24$ y $48 \mathrm{~T} 48$ horas. $£=$ la prueba de $\chi^{2}$ se aplicó para determinar su bondad de ajuste. ${ }^{* * *}=$ significativo con $p \leq 0.001 ; \mathrm{ns}=$ no significativo.

Con relación a las $\mathrm{R}^{2}$ obtenidas entre el número inicial de adultos de $C$. carnea versus su pendiente de supervivencia para ambos experimentos, el tratamiento $0.04 \mu 1 \mathrm{ml}^{-1}$ ácido-aire por 8 horas (del segundo experimento) tuvo la pendiente más acentuada (-1.033) seguidas de los tratamientos testigo - 0.833 y -0.988 del primer y segundo experimento, respectivamente (Cuadro 2 y Figura 4). En los dos experimentos, en los que se les proporción a las larvas como alimento huevos esterilizados con calor de $S$. cerealella, no llegaron a formar ninguna pupa.

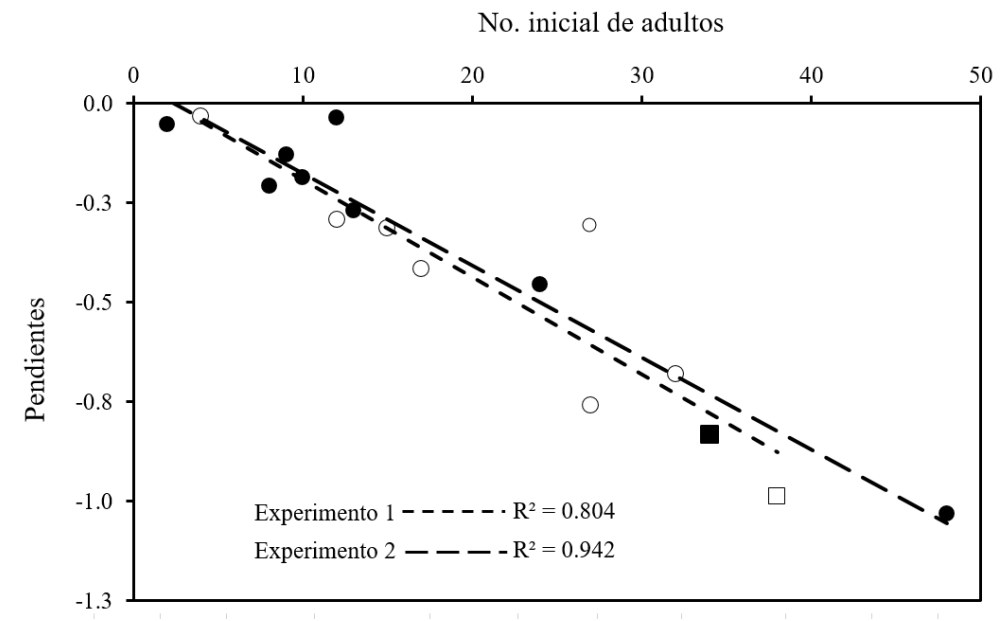

Figura 4. Coeficientes de determinación entre el número inicial de adultos de $C$. carnea y su pendiente de supervivencia. Los cuadrados abierto y cerrado indican los tratamientos testigo o no fumigado del primer y segundo experimento, respectivamente; los círculos abiertos y cerrados representan los tratamientos de fumigación del primer y segundo experimento, respectivamente. 


\section{Bioensayos de fumigación en pupas}

El tiempo y dosis de fumigación fueron significativos $p \leq 0.001$, esto ocurrió para las pupas que permanecieron 7 ó 14 días, conforme se incrementaron el tiempo y dosis de fumigación de las pupas su formación de adultos disminuyó.

Los adultos formados después de fumigar las pupas no fueron acordes con las dosis y tiempos de fumigación, por ejemplo, en los tiempos de incubación 7 ó 14 días, 30 min de fumigación y dosis de $4 \mu \mathrm{ml}^{-1}$ ácido-aire no se generaron adultos, pero sí en tiempos de fumigación menores o mayores a $30 \mathrm{~min}$ (Cuadro 3). La supervivencia de pupas fumigadas que se reflejó en la emergencia de adultos sugiere que el ácido acético no atraviesa la capa externa de la pupa, pues sí lo hiciese la mataría o desinfectaría.

Cuadro 3. Supervivencia $(\%)^{\mathfrak{f}}$ de adultos de $C$. carnea a los 7 y $14 \mathrm{~d}$. El origen de los adultos fuero pupas fumigadas con tres dosis de ácido acético.

\begin{tabular}{|c|c|c|c|c|c|c|c|}
\hline \multirow{2}{*}{$\begin{array}{l}\text { Minutos de } \\
\text { fumigación }\end{array}$} & \multirow{2}{*}{$\begin{array}{l}\text { Días de la } \\
\text { evaluación }\end{array}$} & \multicolumn{6}{|c|}{ Dosis de fumigación en $\mu 1 \mathrm{ml}^{-1}$ ácido-aire } \\
\hline & & \multicolumn{2}{|c|}{0.04} & \multicolumn{2}{|c|}{0.4} & \multicolumn{2}{|c|}{4} \\
\hline 10 & 7 & $€ 100$ & $\mathrm{a}$ & 56 & $\mathrm{e}$ & 33 & $\mathrm{~g}$ \\
\hline 20 & 7 & 89 & $\mathrm{~b}$ & 50 & $\mathrm{f}$ & 39 & $\mathrm{~g}$ \\
\hline 30 & 7 & 92 & $\mathrm{~b}$ & 54 & $\mathrm{e}$ & 0 & $\mathrm{i}$ \\
\hline 60 & 7 & 63 & d & 44 & $\mathrm{f}$ & 56 & $\mathrm{e}$ \\
\hline 120 & 7 & 75 & $\mathrm{c}$ & 25 & $\mathrm{~h}$ & 58 & $\mathrm{~d}$ \\
\hline Testigo & 7 & 36 & $\mathrm{~g}$ & & & & \\
\hline 10 & 14 & 22 & d & 28 & $\mathrm{~d}$ & 0 & $\mathrm{f}$ \\
\hline 20 & 14 & 56 & b & 44 & $\mathrm{c}$ & 28 & $\mathrm{~d}$ \\
\hline 30 & 14 & 77 & $\mathrm{a}$ & 54 & b & 0 & $\mathrm{f}$ \\
\hline 60 & 14 & 13 & e & 19 & e & 56 & $\mathrm{~b}$ \\
\hline 120 & 14 & 58 & $\mathrm{~b}$ & & $\mathrm{f}$ & 17 & $\mathrm{e}$ \\
\hline Testigo & 14 & 23 & d & & & & \\
\hline
\end{tabular}

$\mathfrak{f}^{=}$cada valor representa la media de cuatro repeticiones y cada repetición se conformó con 15 pupas; $€=$ número con diferente letra indica diferencia estadística de acuerdo a la prueba de separación de medias de Duncan con $p=0.05$.

\section{Bioensayos con antimicrobianos en adultos}

Únicamente el tratamiento de cefotaxima a dosis de $1200 \mu \mathrm{g} \mathrm{ml}^{-1}$ permitió que todos los adultos sobrevivieran hasta el día 51. Los 267 adultos sin síntomas al inicio de la aplicación de las sustancias antimicrobianas, representa menos del $5 \%$ de pupas que formaron adultos. En contraste, del número inicial (267) de adultos tratados con sustancias antimicrobianas incluyendo al testigo sobrevivieron 183, después de 51 días, es decir, alrededor de $69 \%$, aunque en los tratamientos con eritromicina y metronidasol sobrevivieron $80 \%$. 


\section{Discusión}

\section{Fumigación del huevo}

La fumigación con ácido acético ha resultado matar microorganismos patógenos de abejas e insectos plaga (Van Engelsdorp et al., 2008; Randall et al., 2011). Aunque la fumigación de los huevos de crisopa mejoró la supervivencia no fue suficiente para eliminar por completo la infección, ya que no sobrevivió $100 \%$ de los adultos.

El agente infeccioso de $C$. carnea se manifestó en larvas, pupas y adultos. Comúnmente, las toxinas de $B$. thuringiensis o la bacteria misma infecta solo estados larvarios de los insectos provocando su muerte de 2 a 5 y de 7 a 10 días, respectivamente (Broderick et al., 2006).

De los huevos no fumigados nacieron el doble de adultos que de huevos fumigados (Figura 3 izquierda) lo que sugiere que la fumigación favorece la mortandad de los huevos y al mismo tiempo una selección de adultos que sobrevivirán más tiempo y en proporción (Figura 3 derecha). Sin embargo, a mayor número inicial de adultos que se confinaron en celdas individuales las tasas de mortandad fueron más acentuadas (Cuadro 2 y Figura 4).

Una posible causa de la infección que explique la muerte de las crisopas que permanecieron en celdas individuales después de dos semanas, pudo ser el alimento contenido en las celdas, en donde el posible agente infeccioso pudo reproducirse y reinfectar los adultos. Considérese que dicho alimento, no fue sustituido durante las cinco semanas en que los insectos adultos permanecieron bajo observación.

El alimento pudo favorecer el desarrollo de microrganismos relacionados directa o indirectamente con la infección y muerte de las crisopas. Esto lo sugiere la supervivencia casi de $100 \%$ de los adultos a los 16 días en 18 de 21 tratamientos donde se evaluaron los antimicrobianos (datos no mostrados) y donde hubo recambio de alimento y asepsia de los vasos donde permanecieron las crisopas. Aunque en este trabajo, no se puede atribuir la presencia de B. thuringiensis como causa de la infección de los adultos u otro estadio de $C$. carnea, se sabe que esta bacteria por sí sola o en presencia de bacterias entéricas puede matar larvas de crisopas (Broderick et al., 2009; Johnston y Crickmore, 2009).

Dentro de huevos, larvas y adultos de insectos incluyendo Chrysoperla spp., habitan levaduras, bacterias que les ayudan a digerir su alimento (Chen et al., 2006), complementan su dieta o deficiencias nutricionales (Gibson y Hunter, 2005; Ben-Yosef et al., 2010). En suma, existen por lo menos diez factores extrínsecos que afectan la relación selectividad y dosis-respuesta de las toxinas de $B$. thuringiensis hacia insectos, tales como sus microbiotas, factores nutricionales, respuesta inmunológica, entre otros (Lawo et al., 2010; Then, 2010; Grenier, 2012). Los huevos de S. cerealella utilizados para alimentar a las larvas que provenían de los huevos fumigados podrían también albergar inóculo infeccioso o microorganismos que favorecieran la infección.

En este trabajo, se intentó eliminar la infección potencial al esterilizar los huevos de $S$. cerealella para alimentar las larvas de $C$. carnea, pero éstas no sobrevivieron con este alimento. Resultados obtenidos por Fletcher (2016) muestran que larvas de $C$. carnea se infectaron y murieron al 
alimentarse con huevos del insecto Adalia bipunctata L. infectados con el patógeno Nosema adaliae Steele \& Bjørnson. Las crisopas también pueden infectarse y morir al estar en contacto con bacterias, por ejemplo, Chrysoperla externa Hagen murió por bacterias aisladas de Phyllocnistis citrella Stainton (presas de la crisopa) (Meca et al., 2009), mientras que C. carnea murió por bacterias patógenas de humanos Pseudomonas aureoginosa y P. putida (Fernández et al., 2015).

\section{Fumigación de pupas}

Algunas pupas que se fumigaron hasta dos horas, que fue el tiempo máximo y a la dosis de $4 \mu 1$ $\mathrm{ml}^{-1}$ ácido-aire sobrevivieron, lo que sugiere que algunas toleran la fumigación. En contraste, la marcada variación de emergencia y sobrevivencia de las crisopas provenientes de las pupas expuestas a distintas dosis-tiempo de fumigante sugiere que tuvieron un marcado deterioro y/o muerte antes de aplicar los tratamientos (Cuadro 3).

La trasmisión vertical (adulto $\rightarrow$ huevo $\rightarrow$ larva $\rightarrow$ pupa $\rightarrow$ adulto) de microorganismos benéficos o perjudiciales de las especies de Chrysoperla es conocida (Sung-Oui et al., 2004; Hemalatha, 2015), ello podría explicar la trasmisión del agente infeccioso con la subsecuente mortandad de huevo, pupas, larvas y adultos.

\section{Aplicación de sustancias antimicrobianas en adultos}

La asepsia y la eliminación de crisopas que murieron los dos primeros días durante los tratamientos de sustancias antimicrobianas, posiblemente permitieron mantener $C$. carnea con los mayores porcentajes de supervivencia que en los experimentos anteriores. Incluso en el tratamiento con 1 $200 \mu \mathrm{g} \mathrm{ml}^{-1}$ de cefotaxima la muerte de adultos o síntomas de la infección no se manifestaron. Los antibióticos se han utilizado para eliminar las bacterias y al mismo tiempo, determinar su papel incluyendo las bacterias endosimbióticas en los insectos; las dosis utilizadas que afectaron a los insectos fueron desde $10 \mu \mathrm{g} \mathrm{ml}^{-1}$ hasta $5 \mathrm{mg} \mathrm{ml}^{-1}$ (Broderick et al., 2006; Ben-Yosef et al., 2010; Lin et al., 2015).

Insectos entomófagos como Chrysoperla spp., tienen efectos negativos en su ciclo de vida cuando se alimentan de sus presas si estas últimas se han alimentado de cultivos transgénicos que expresan toxinas de B. thuringiensis (Hilbeck et al., 1998; Dutton et al., 2003). En contraste, otros trabajos indican que Chrysoperla no es afectada al depredar presas que han consumido plantas transgénicas (Tian et al., 2013; Carvalho et al., 2012; Meissle et al., 2014) por ello, no está del todo claro el papel de $B$. thuringiensis sobre las crisopas.

Tampoco sabemos el papel de B. thuringiensis encontrado dentro de adultos muertos de C. carnea, pero el saberlo, podría ayudar a esclarecer sí la bacteria podría ser patógena o no sobre estos insectos desde huevo hasta adulto. La tolerancia de los huevos y pupas a la fumigación con AA y la de los adultos a los antimicrobianos, podría evaluarse en el futuro para eliminar organismos no deseables en la producción masiva de insectos benéficos distintos a la crisopa.

Nuestro desconocimiento cuantitativo de la infección y su falta de control en huevo, pupa y adulto generó una inconsistencia dosis-tiempos de fumigación y dosis de antimicrobianos versus sobrevivencia de adultos. 


\section{Conclusiones}

En este trabajo, B. thuringiensis aislado de cadáveres de $C$. carnea no es suficiente para asociarlo como la causa de la infección y se requeriría un estudio más detallado para determinar su papel en la muerte de estos insectos. El efecto del ácido acético en los huevos fumigados se tradujo en menos adultos obtenidos en comparación a huevos no fumigados, pero los adultos de huevos fumigados sobrevivieron el doble que los adultos de huevos no fumigados, después de cinco semanas mostrando por tanto un cierto efecto beneficioso sobre la supervivencia de C. carnea.

Algunas pupas lograron sobrevivir, generar adultos y sobrevivir estos hasta 14 días, después de fumigar las pupas hasta $120 \mathrm{~min}$ con dosis de ácido acético de $4 \mu \mathrm{ml}^{-1}$ ácido-aire. Los tratamientos con sustancias antimicrobianas junto con la asepsia permitieron la mayor supervivencia de crisopas en comparación a pupas y huevos fumigados.

\section{Literatura citada}

Aguino de Muro, M. and Priest, F. G. 1993. Phylogenetic analysis of Bacillus sphaericus and development of an oligonucleotide probe specific for mosquito-pathogenic strains. FEMS Microbiol. Lett. 112:205-210.

Ben-Yosef, M.; Aharon Y.; Jurkevitch, E. and Yuval, B. 2010. Give us the tools and we will do the job: symbiotic bacteria affect olive fly fitness in a diet-dependent fashion. Proceedings of the Royal Society of London B. Biol. Sci. 277:1545-1552.

Bravo, A. S.; Sarabia, L. L.; Ontiveros, H.; Abarca, C.; Ortiz, A.; Ortiz, M.; Lina, L.; Villalobos, F. J.; Peña, G.; Núñez-Valdez, M. E.; Soberón, M. and Quintero, R. 1998. Characterization of cry genes in a Mexican Bacillus thuringiensis strain collection. Appl. Environ. Microbiol. 64:4965-4972.

Broderick, N. A.; Raffa, K. F. and Handelsman, J. 2006. Midgut bacteria required for Bacillus thuringiensis insecticidal activity. Proceedings of the National Academy of Sciences 103:15196-15199.

Broderick, N. A.; Robinson, C. J.; McMahon, M. D.; Holt, J.; Handelsman, J. and Raffa, K. F. 2009. Contributions of gut bacteria to Bacillus thuringiensis-induced mortality vary across a range of Lepidoptera. BMC Biology. 7:11. doi:10.1186/1741-7007-7-11.

Carreras-Solís, B. 2009. Obtención de aislados de Bacillus thuringiensis Berliner autóctonos de Cuba. Fitosanidad. 13:109-116.

Carvalho, V. F. P.; Vacari, A. M.; Pomari, A. F.; De Bortoli, C. P.; Ramalho, D. G. and De Bortoli S. A. 2012. Interaction between the predator Podisus nigrispinus Hemiptera: Pentatomidae and the entomopathogenic bacteria Bacillus thuringiensis. Environ. Entomol. 41:1454-1461.

Cerón, J.; Ortíz, A.; Quintero, R.; Güereca, L. and Bravo, A. 1995. Specific PCR primers directed to identify cryI and cryIII genes within a Bacillus thuringiensis strain collection. Appl. Environ. Microbiol. 6:3826-3831.

Chen, T. Y.; Chu, C. C.; Hu, C.; Mu, J. Y.; Mu, J. Y. and Henneberry, J. A. 2006. Observations on midgut structure and content of Chrysoperla carnea Neuroptera: Chrysopidae. Annals Entomological Society America. 99:917-919.

Dutton, A.; Klein, H.; Romeis, J. and Bigler, F. 2003. Prey-mediated effects of Bacillus thuringiensis spray on the predator Chrysoperla carnea in maize. Biological Control. 26:209-215. 
Fernández, M.; Porcel, M.; de la Torre, J.; Molina-Henares, M. A.; Daddaoua, A.; Llamas, M. A. and Alaminos, M. 2015. Analysis of the pathogenic potential of nosocomial Pseudomonas putida strains. Frontiers in Microbiology. 6:871. doi: 10.3389/fmicb.2015.00871.

Fletcher, A. 2016. Horizontal transmission of the microsporidium, Nosema adaliae, from the two spotted lady beetle, Adalia bipunctata, to the Green lacewing, Chrysoperla carnea. A Thesis Submitted to Saint Mary's University, Halifax, Nova Scotia.

Gibson, C. M. and Hunter, S. M. 2005. Reconsideration of the role of yeasts associated with Chrysoperla green lacewings. Biological Control. 32:57-64.

Grenier, S. 2012. Artificial rearing of entomophagous insects, with emphasis on nutrition and parasitoids-general outlines from personal experience. Karaelmas Sci. Eng. J. 2:1-12.

Hemalatha, B. N. 2015. Studies on characterization of endosymbionts of Chrysoperla zastrowi sillemi Esben Peterson and their role on the fitness attribute. Doctoral Thesis. University of Mysore, India.

Hilbeck, A.; Baumgartner, M.; Fried, P. M. and Bigler, F. 1998. Effects of transgenic Bacillus thuringeinsis corn-fed prey on mortality and development time of immature Chrysoperia carnea Neuroptera: Chrysopidae. Environ. Entomol. 27:480-487.

Johnston, P. R. and Crickmore, N. 2009. Gut bacteria are not required for the insecticidal activity of Bacillus thuringiensis toward the tobacco hornworm, Manduca sexta. Appl. Environ. Microbiol. 75:5094-5099.

Katase, M.; Kubo, C.; Ushio, S.; Ootsuka, E.; Takeuchi, T. and Mizukubo T. 2009. Nematicidal activity of volatile fatty acids generated from wheat bran in reductive soil disinfestation. $\mathrm{J}$. Nematol. Res. 39:53-62.

Kleespies, R. G.; Huger, A. M. and Zimmermann, G. 2008. Database on arthropod diseases. http://arthropodenkrankheiten.jki.bund.de/ergebordung_e.php?pageNum_rsvoll=1 and totalRows_rsvoll=19and selordnung=Neuroptera.

Lawo, N. C.; Wäckers F. L. and Romeis, J. 2010. Characterizing indirect prey-quality mediated effects of a Bt crop on predatory larvae of the green lacewing, Chrysoperla carnea. J. Insect Physiol. 56:1702-1710.

Lin, X. L.; Kang, Z. W.; Pan, Q. J. and Liu, T. X. 2015. Evaluation of five antibiotics on larval gut bacterial diversity of Plutella xylostella Lepidoptera: Plutellidae. Insect Sci. 22:619-628.

McEwen, P. K.; New, T. R. and Whittington, A. E. 2007. Lacewings in the crop environment. Cambridge University Press.

Meca, A.; Sepúlveda, B.; Ogoña, J. C.; Grados, N.; Moret, A.; Morgan, M. and Tume, P. 2009. In vitro pathogenicity of Northern Peru native bacteria on Phyllocnistis citrella Stainton Gracillariidae: Phyllocnistinae, on predator insects Hippodamia convergens and Chrysoperla externa, on Citrus aurantiifolia Swingle and white rats. Spanish J. Agric. Res. 7:137-145.

Meissle, M.; Zünd, J.; Waldburger, M. and Romeis, J. 2014. Development of Chrysoperla carnea Stephens Neuroptera: Chrysopidae on pollen from Bt-transgenic and conventional maize. Scientific reports, 4.

Momma, N.; Yamamoto, K.; Simandi, P. and Shishido, M. 2006. Role of organic acids in the mechanisms of biological soil disinfestations BSD. J. Gen. Plant Pathol. 72:247-252.

Randall, P.; Sholberg, P.; Judd, G. and Cossentine, J. 2011. Acetic acid fumigation of fruit storage bins to control diapausing codling moth larvae. HortSci. 46:1634-1639.

SAS Institute 2003. Statistical Analysis System version 9.1. SAS Institute Inc., Cary, North Caroline. 
Sholberg, P. L. 2009. Control of postharvest decay by fumigation with acetic acid or plant volatile compounds In: Sivakumar, D. (Ed.). New Trends in Postharvest Management of Fresh Produce I Fresh Produce 3 Special Issue. 1:80-86.

Sung-Oui, S.; Gibson, M. C. and Blackwell, M. 2004. Metschnikowia chrysoperlae sp. nov Candida picachoensis sp. nov. \& Candida pimensis sp. nov isolated from the green lacewings Chrysoperla comanche and Chrysoperla carnea Neuroptera: Chrysopidae. International Journal of Systematic and Evolutionary Microbiology. 54:1883-1890.

Taber, W. S. 2011. Two parasites of the green lacewing Chrysopa chi Fitch Neuroptera: Chrysopidae: One species known and one species unidentified. Southwestern Entomol. 36:91-102.

Then, C. 2010. Risk assessment of toxins derived from Bacillus thuringiensis-synergism, efficacy, and selectivity. Environ. Sci. Pollution Res. 17:791-797.

Tian, J. C.; Wang, X. P.; Long, L. P.; Romeis, J.; Naranjo, S. E.; Hellmich, R. L. and Shelton, A. M. 2013. Bt crops producing Cry1 Ac, Cry2 Ab and Cry1F do not harm the green lacewing, Chrysoperla rufilabris. PloS One. 8: e60125.

Van Engelsdorp, D.; Underwood, R. M. and Cox-Foster, D. L. 2008. Short-term fumigation of honeybee Hymenoptera: Apidae colonies with formic and acetic acids for the control of Varroa destructor Acari: Varroidae. J. Econ. Entomol. 101:256-264. 